\title{
Сорбционные свойства модифицированных клиноптилолитовыми породами желатиновых пленок
}

\author{
(C) 2020 Дабижа О.Н. ${ }^{1,2}$, Битюцкая М.С. ${ }^{1}$ \\ ${ }^{1}$ Забайкальский государственный университет, Чита \\ ${ }^{2}$ Забайкальский институт железнодорожного транспорта, Чита
}

Поступила в редакцию 11.05.2020 г.

DOI: $10.17308 /$ sorpchrom.2020.20/3056

Статья посвящена проблеме получения модифицированных желатиновых пленок с регулируемой набухаемостью и растворением. В качестве модификатора использовали механоактивированные высококремнеземные (силикатный модуль больше 4) клиноптилолитовые породы, высокодисперсную фракцию с размером частиц не более 71 мкм. Наличие в клиноптилолите поверхностных силанольных групп способных к взаимодействию с карбоксильными или аминогруппами макромолекул желатина посредством межмолекулярных водородных связей непосредственно либо через прослойку молекулы воды позволяет рассматривать возможность дополнительного усиления структуры. Цель работы заключалась в синтезе полимер-минеральных материалов на основе желатина и механоактивированных клиноптилолитовых пород, а также изучении степени набухания и растворения полимерминеральных пленок в водных средах.

Наполненные полимерные системы получали смешиванием желатинового раствора с водной суспензией высокодисперсной фракции цеолитов. Взаимодействие желатина с механоактивированным клиноптилолитовым наполнителем будет улучшать межфазную адгезию и ограничивать подвижность полимерных цепей, что эквивалентно образованию дополнительных узлов структурной сетки. Методами оптической микроскопии и гравиметрии изучены морфология модифицированных желатиновых пленок и сорбция паров воды и паров насыщенных растворов хлорида натрия и хлорида калия.

Установлено наличие коагуляционных структур при содержании минерального дисперсного наполнителя 0.5 мас. \% и сферическая форма его частиц, относительно равномерных распределенных в объемах 2.5 и 5 г/дл желатиновых матриц. Выявлено, что пленки лучше всего поглощают пары воды, чем пары насыщенных растворов электролитов. Установлено, что добавление 0.5 мас. \% механоактивированных клиноптилолитовых пород в раствор желатина концентрации 5 г/дл позволяет получать пленки с пониженной степенью набухания не менее чем в 8 раз в парах воды и не менее чем в 23 раза в парах хлорида натрия или хлорида калия. С учетом безопасности и отличных сорбционных свойств клиноптилолитовых пород, полученные в настоящей работе результаты можно рекомендовать к применению в медицине и ветеринарии.

Ключевые слова: желатин, цеолиты, клиноптилолит, пленки, сорбционные свойства, электролиты, набухание в воде, оптическая микроскопия, морфология.

\section{Введение}

Желатин представляет собой линейный высокоасимметричный полипептидный полимер белковой природы. Желатиновые пленки широко применяются в фотографической [1], фармацевтической [2,3] и пищевой промышленностях. Однако одним из главных недостатков желатиновых капсул является низкая механическая прочность [4] и высокая чувствительность к влаге. За счет внутренних осмотических эффектов, связанных с зарядами полимера и противоионов, набухание будет тем существеннее, чем выше заряд на молекулах желатина, что согласуется с эксперимен- 
тальными данными (рис. 1) [5]. Процесс поглощения желатином воды прекращается, когда $\alpha$-цепи утрачивают свою гибкость [6]. Модифицирование желатина гидрофобным наполнителем позволит регулировать скорость его растворения в водной среде и расширить области практического использования. Так, добавление гидрофильного или гидрофильно-гидрофобного кремнезема в желатиновые пленки приводит к уменьшению смачиваемости материалов и их сродства к воде, замедлению набухания и растворения [7].

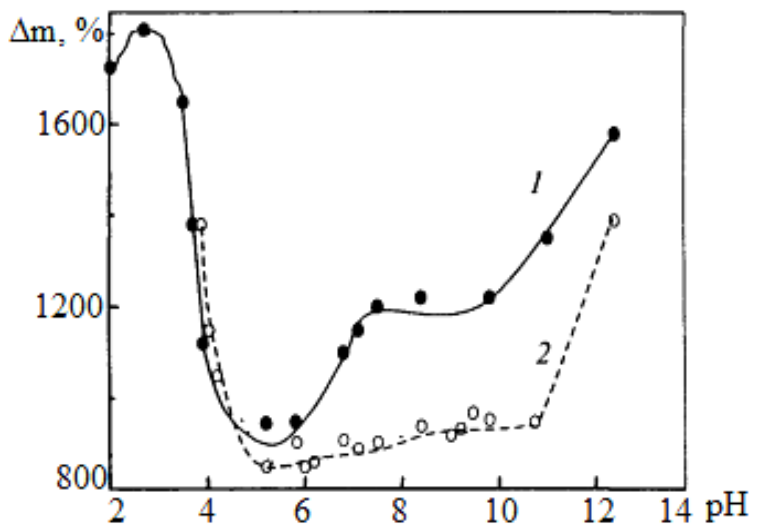

Рис. 1. Зависимость набухания «щелочного» (1) и «кислотного» (2) желатина в воде от $\mathrm{pH}[5]: \Delta \mathrm{m}-$ прирост массы

Fig. 1. The dependence of the swelling of "alkaline" (1) and "acid" (2) gelatin in water with $\mathrm{pH}[5]: \Delta \mathrm{m}-$ mass gain

Природные цеолиты эффективно применяются в ветеринарии для профилактики и лечения незаразных болезней, кожных заболеваний [8], в медицине - для лечения гнойных ран и ожогов [9]. Нетоксичный, доступный и недорогой природный цеолит - клиноптилолит является перспективным наполнителем модифицированных желатиновых пленок [3, 10-12]. Наличие в клиноптилолите поверхностных силанольных (三Si-OH) групп, способных к электростатическому взаимодействию с положительно заряженными участками макромолекул желатина и к образованию межмолекулярных водородных связей с карбоксильными или аминогруппами [7] непосредственно, либо через прослойку молекул воды, позволяет рассматривать возможность дополнительного усиления структуры. Механоактивация цеолитов за счет накопления дефектов является эффективным способом повышения их реакционной способности и сорбционных свойств $[13,14]$. Взаимодействие желатина с механоактивированным клиноптилолитовым наполнителем будет улучшать межфазную адгезию и ограничивать подвижность полимерных цепей, что эквивалентно образованию дополнительных узлов структурной сетки [15]. Таким образом можно получить сорбционный материал с регулируемой скоростью набухания и растворения в водной фазе.

Цель настоящей работы: синтез полимер-минеральных материалов на основе желатина и механоактивированных клиноптилолитовых пород, а также изучение степени набухания и растворения полимер-минеральных пленок в водных средах.

\section{Эксперимент}

В работе использовали желатин пищевой (ГОСТ 11293-89) и природные цеолиты - высококремнистые клиноптилолит-стильбитовая (I) и клиноптилолитовая (II) породы (Холинское и Шивыртуйское месторождения, Забайкальский край). Химиче- 
ский состав, w, \%: $\mathrm{SiO}_{2}$ 74.94; $\mathrm{Al}_{2} \mathrm{O}_{3}$ 11.92; $\mathrm{TiO}_{2}$ 0.12; $\mathrm{Fe}_{2} \mathrm{O}_{3}$ 0.67; $\mathrm{CaO} 1.54 ; \mathrm{MgO} 0.18$; $\mathrm{Na}_{2} \mathrm{O}$ 1.72; $\mathrm{K}_{2} \mathrm{O} 4.24$ - для образца I; $\mathrm{SiO}_{2}$ 69.42; $\mathrm{Al}_{2} \mathrm{O}_{3}$ 13.06; $\mathrm{TiO}_{2}$ 0.34; $\mathrm{Fe}_{2} \mathrm{O}_{3}$ 2.14; $\mathrm{CaO} 3.00 ; \mathrm{MgO}$ 0.84; $\mathrm{Na}_{2} \mathrm{O} 1.30 ; \mathrm{K}_{2} \mathrm{O} 2.95$ - для образца II. В качестве примесного минерала, исходные породы содержат кварц.

Воздушно-сухие клиноптилолитовые породы помещали в дробилку BOYD MK III и измельчали 2 минуты до крупности $\mathrm{r}<2.00$ мм, далее диспергировали 3 минуты с помощью дисковой вибрационной мельницы Essa LM2-P до размера частиц не более 0.50 мм. Из полученного минерального порошка высеивали высокодисперсную фракцию (частицы размером не более 71 мкм), которую использовали в качестве высокодисперсного наполнителя желатина.

2.5 и 5.0 г желатина растворяли в $100 \mathrm{~cm}^{3}$ дистиллированной воды и нагревали на водяной бане при перемешивании в течение 20 мин. В готовый полимерный раствор постепенно добавляли $5 \mathrm{~cm}^{3}$ суспензии клиноптилолитовой породы (0.120.50 мас. \%) и перемешивали на магнитной мешалке в течение еще 10 мин. Содержание наполнителей в полимерной матрице (табл. 1) подбирали в соответствии с возможностью равномерного объемного наполнения получаемых композиций.

Таблица 1. Состав пленочных композиций

Table 1. Composition of films

\begin{tabular}{|c|c|c|c|}
\hline $\begin{array}{c}\text { Содержание желати- } \\
\text { на, г/100 см }\end{array}$ & Наполнители & $\begin{array}{c}\text { Содержание напол- } \\
\text { нителя, мас. \% }\end{array}$ & $\begin{array}{c}\text { Наименования об- } \\
\text { разцов }\end{array}$ \\
\hline \multirow{7}{*}{2.5} & - & 0 & 2.5 \\
\hline & \multirow{3}{*}{$\begin{array}{c}\text { клиноптилолит- } \\
\text { стильбитовая порода }\end{array}$} & 0.12 & 2.5-Ia \\
\hline & & 0.25 & $2.5-\mathrm{Ib}$ \\
\hline & & 0.50 & $2.5-\mathrm{Ic}$ \\
\hline & \multirow{3}{*}{$\begin{array}{c}\text { клиноптилолитовая } \\
\text { порода }\end{array}$} & 0.12 & 2.5-IIa \\
\hline & & 0.25 & $2.5-\mathrm{IIb}$ \\
\hline & & 0.50 & 2.5-IIc \\
\hline \multirow{7}{*}{5.0} & - & 0 & 5 \\
\hline & \multirow{3}{*}{$\begin{array}{c}\text { клиноптилолит- } \\
\text { стильбитовая порода }\end{array}$} & 0.12 & 5-Ia \\
\hline & & 0.25 & $5-\mathrm{Ib}$ \\
\hline & & 0.50 & 5 -Ic \\
\hline & \multirow{3}{*}{$\begin{array}{c}\text { клиноптилолитовая } \\
\text { порода }\end{array}$} & 0.12 & 5-IIa \\
\hline & & 0.25 & $5-\mathrm{IIb}$ \\
\hline & & 0.50 & 5-IIc \\
\hline
\end{tabular}

Желатин-цеолитные композиции в виде тонких пленок готовили методом полива. $1 \mathrm{~cm}^{3}$ раствора полимера или суспензии выливали тонким слоем на поверхность предметного стекла и полипропиленовой подложки и высушивали в воздушной атмосфере при $25{ }^{\circ} \mathrm{C}$ в течение нескольких часов и нескольких суток, соответственно.

Морфологию исходных и модифицированных полимерных пленок, нанесенных на стеклянную поверхность, изучали методом оптической микроскопии микроскопом МБС-9 (общее увеличение × 100).

Процессы сорбции паров воды, а также паров насыщенных растворов электролитов $\mathrm{NaCl}$ и $\mathrm{KCl}$ образцами пленок, полученными на полипропиленовых подложках, изучали при $25^{\circ} \mathrm{C}$ при величинах относительной влажности среды 17.6 и $85.7 \%$ [16]. Образцы массой $\mathrm{m}=0.01$ г помещали в эксикаторы, наполненные водой или электролитами. Изменения массы образцов фиксировали с точностью $\pm 10^{-4}$ г периодическим взвешиванием на аналитических весах при $25^{\circ} \mathrm{C}$ в течение четырех суток [17]. Величину сорбции ( $\alpha$ г/г) рассчитывали по стандартному уравнению как 
отношение изменения массы в результате сорбции низкомолекулярной жидкости к исходной массе образца.

\section{Обсуждение результатов}

Исследуемые композиции на основе желатина и природных цеолитов представляют собой усиленные эластичные пленки с визуально видимым распределением минеральных частиц.

На оптических изображениях наблюдается фазовая гетерогенность и сферическая форма частиц дисперсных наполнителей (рис. 2). При содержании минеральных частиц 0.5 мас. \% в желатиновых системах с концентрацией полимера 2.5 и 5 г/дл легко увидеть образование коагуляционных структур-агломератов частиц (образцы 2.5-Іс; 2,5-IIc; 5-Ic; 5-IIc). Следовательно, структурирование или образование надмолекулярной структуры посредством избирательного сшивания желатиновых макромолекул с участием частиц клиноптилолитовых пород происходит при их содержании в системе 0.5 мас. \%.

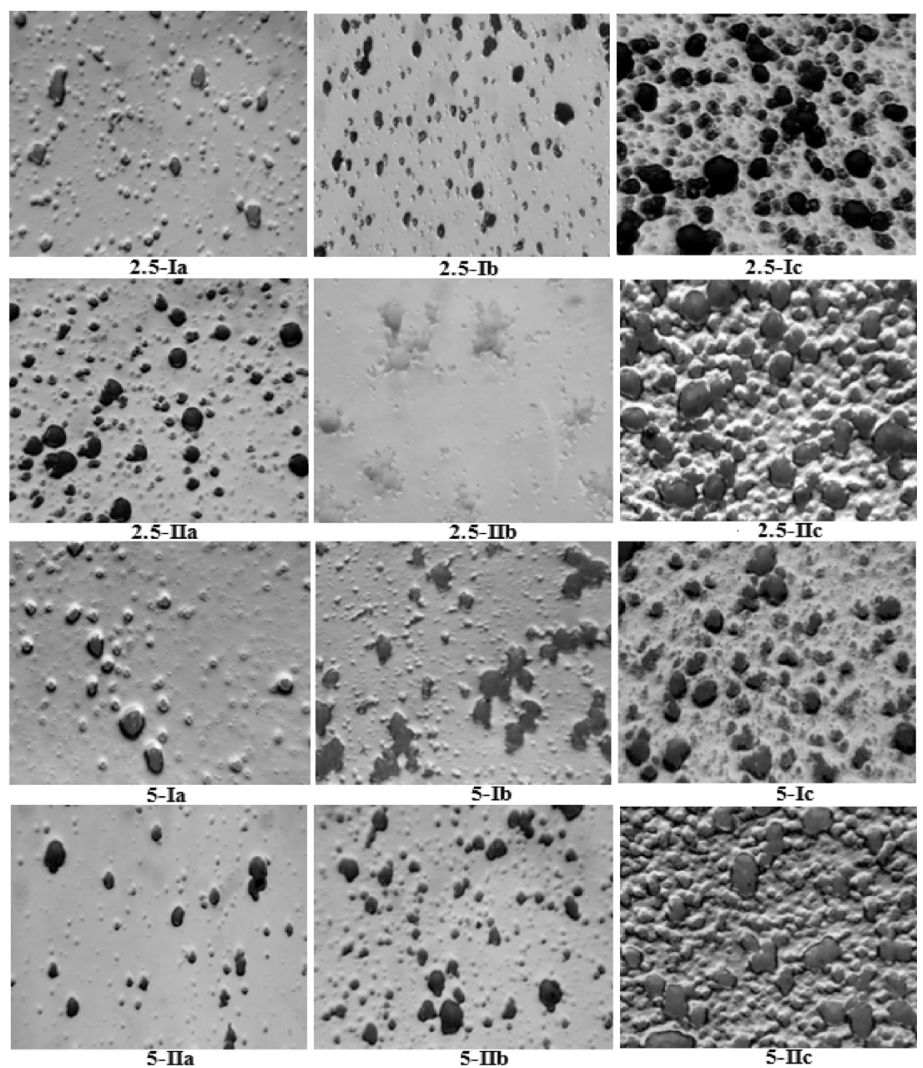

Рис. 2. Оптическое изображение желатиновых пленок, наполненных клиноптилолитовыми породами (увеличение $\times 100$ )

Fig. 2. Optical image of gelatin films filled with clinoptilolite rocks (magnification $\times 100$ )

Способность к сорбции низкомолекулярных веществ, в частности растворителей, является важной характеристикой структуры полимеров [15] и определяет возможность их использования в качестве матрицы для введения биологически активных веществ [2]. Вода оказывает сильное модифицирующее действие на желатин, внедряясь в межмолекулярное пространство белка и адсорбируясь на полярных 
группах [18]. Кроме того, цеолиты также обладают сорбционными свойствами [13] и отлично поглощают воду. Кинетические кривые сорбции паров воды исследуемыми образцами приведены на рисунке 3. Сложный характер сорбционных кривых обусловлен процессами комплексообразования с участием функциональных групп желатина, молекул воды и силанольных групп клиноптилолита. Снижение сорбции может вызывать исключение функциональных групп из сорбционного процесса вследствие их взаимодействия друг с другом. Однако в процессе сорбции становятся доступными отдельные активные центры, поэтому в определенный момент времени наблюдается увеличение сорбции (кривые 5 и 5-Іа рис. 3). Характер сорбции паров воды желатиновой пленкой объясняется, кроме комплексообразования, полидисперсностью биополимера, различием в гибкости его полимерных цепей и изменениями их конформаций.
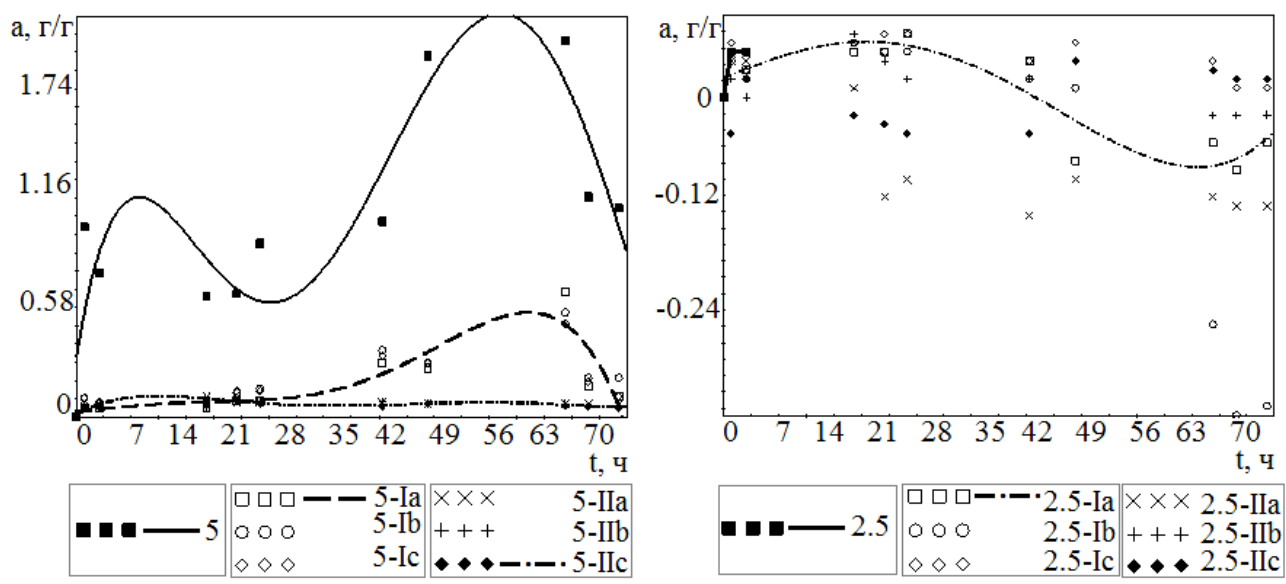

Рис. 3. Кинетические кривые сорбции паров воды пленочными образцами: линиями обозначены аппроксимирующие кривые, относящиеся к исходным ненаполненным полимерным пленкам и к композициям с наибольшим изменением сорбции)

Fig. 3. Kinetic curves of vapour sorption of water by film samples: the lines indicate the approximating curves related to the initial unfilled polymer films and to compositions with the most significant change in sorption)

Анализ рис. 3 показал, что под воздействием паров воды набухание модифицированных полимерных пленок, содержащих клиноптилолит-стильбитовый (I) и клиноптилолитовый (II) наполнители, уменьшается по сравнению с желатиновой пленкой, полученной из 5 г/дл водного раствора. Желатиновая пленка, полученная из 2.5 г/дл водного раствора сохраняется в течение нескольких часов, после чего, в результате сорбции воды, растворяется. В результате модифицирования такого полимерного раствора клиноптилолитовыми породами образцы полимерных пленок сохраняются не менее 71 часа. При содержании дисперсного наполнителя 0.12 мас. \% полимерные системы высушиваются, или имеют отрицательную степень набухания, после 46 часов сорбции. Найдено, что степень набухания наполненной полимерной пленки 2.5-IIc в парах воды в течение 72 часов держится в пределах $\pm 4 \%$. Следовательно, наличие фракции клиноптилолитовой породы размером частиц не более 71 мкм способствует образованию дополнительных физических связей в геле, уменьшая подвижность полипептидных цепей и способность желатинового материала к набуханию.

На рисунке 4 приведены кинетические кривые сорбции паров насыщенного раствора хлорида натрия исследуемыми полимерными пленками. Выявлено, что 
пленка, полученная из наполненного 0.12 мас. \% клиноптилолит-стильбитовой породы раствора желатина концентрации 5 г/дл (5-Іа) проявляет более высокую степень набухания в парах насыщенного раствора $\mathrm{NaCl}$. Самыми низкими показателями степени набухания в этой среде обладают образцы наполненные 0.5 мас. \% клиноптилолитовой породы (5-IIc; 2.5-IIc).
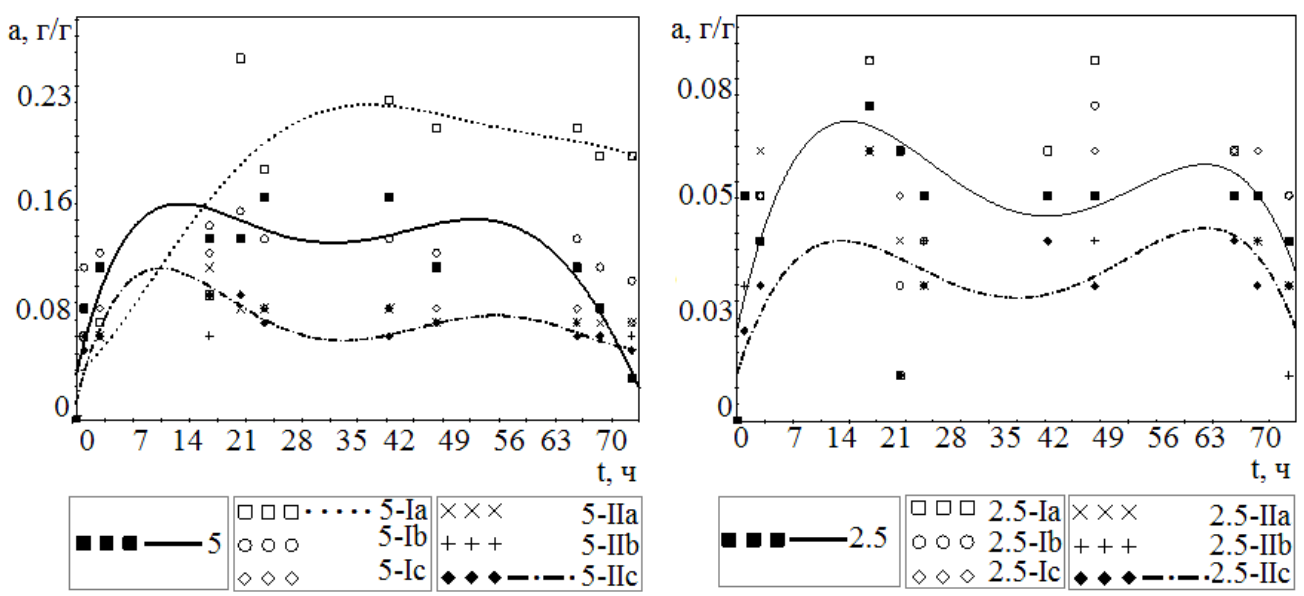

Рис. 4. Кинетические кривые сорбции паров насыщенного раствора хлорида натрия пленочными образцами (линиями обозначены аппроксимирующие кривые, относящиеся к исходным ненаполненным полимерным пленкам и к композициям с наибольшим изменением сорбции)

Fig. 4. Kinetic curves of vapour sorption of saturated sodium chloride solution by film samples (the lines indicate the approximating curves related to the initial unfilled polymer films and to compositions with the most significant change in sorption)

Обнаружено (рис. 5), что в сравнении с немодифицированными полимерными пленками 5 и 2.5, минимальными значениями степени набухания в парах насыщенного раствора $\mathrm{KCl}$ обладают образцы 5-IIc и 2.5-Ib, а максимальной - 2.5-IIb.
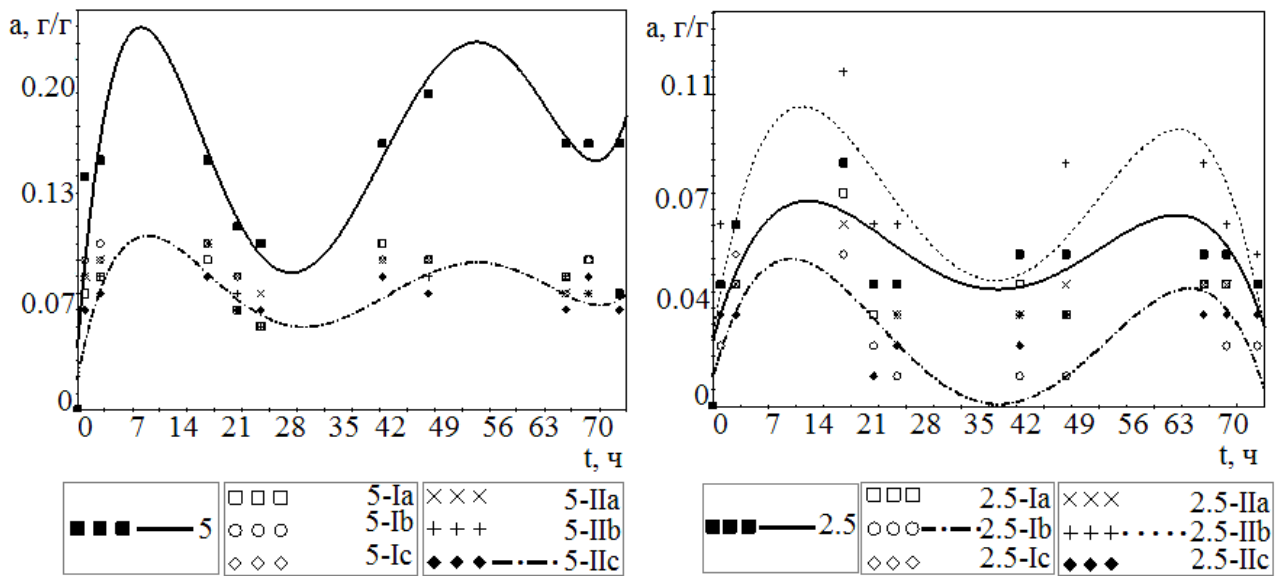

Рис. 5. Кинетические кривые сорбции паров насыщенного раствора хлорида калия пленочными образцами (линиями обозначены аппроксимирующие кривые, относящиеся к исходным ненаполненным полимерным пленкам и к композициям с наибольшим изменением сорбции)

Fig. 5. Kinetic curves of vapour sorption of saturated potassium chloride solution by film samples (the lines indicate the approximating curves related to the initial unfilled polymer films and to compositions with the most significant change in sorption) 
По величине степени набухания исследуемые желатиновые пленки можно расположить в следующие ряды:

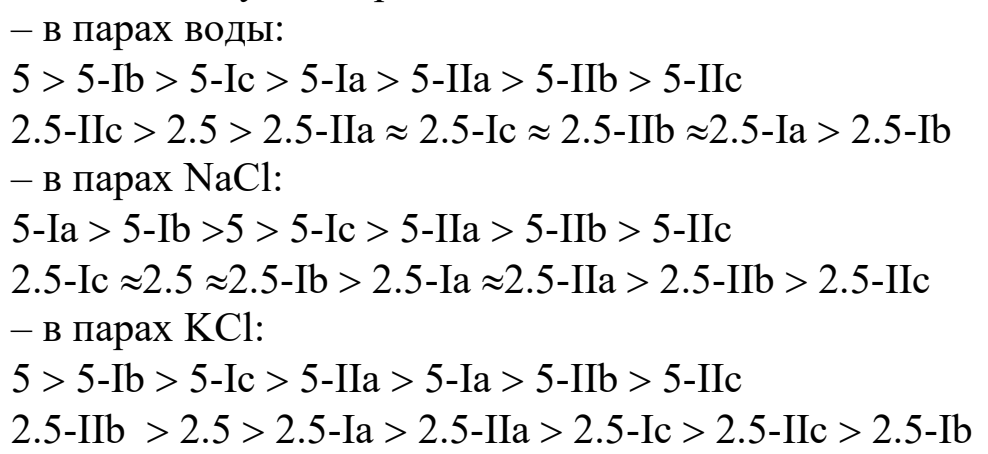

Следует заключить, что полимерная пленка, полученная на основе водного раствора желатина с концентрацией 5 г/дл, наполненного 0.5 мас. \% клиноптилолитовой породы по совокупности опытов имеет наименьшую степень набухания по сравнению с ненаполненной системой с аналогичным содержанием полимера. Обнаружено, что наполнители клиноптилолит-стильбитовой породы (I) обладают большей сорбционной активностью, чем клиноптилолитовой (II).

\section{Заключение}

При наполнении желатина высокодисперсными клиноптилолитовыми породами (фракция частиц размером не более 71 мкм) получены усиленные полимерминеральные пленки.

Методом оптической микроскопии установлено наличие коагуляционных структур при содержании минерального дисперсного наполнителя 0.5 мас. \% и сферическая форма его частиц, относительно равномерных распределенных в объемах 2.5 и 5 г/дл желатиновых матриц. Выявлено, что пленки лучше всего поглощают пары воды, чем пары насыщенных растворов электролитов. Установлено, что добавление 0.5 мас. \% механоактивированных клиноптилолитовых пород в раствор желатина концентрации 5 г/дл позволяет получать пленки с пониженной степенью набухания не менее чем в 8 раз в парах воды, не менее чем в 2-3 раза в парах хлорида натрия или хлорида калия.

Учитывая отсутствие токсичных и канцерогенных свойств, доступность и низкую стоимость, сорбционные свойства природных цеолитов, а также биосовместимость желатина, в дальнейшем полученные желатиновые пленки, наполненные механоактивированным клиноптилолитом, обладающие пониженной набухаемостью, могут быть рекомендованы к применению в медицине и ветеринарии.

\section{Список литературы}

1. Азизов И.К., Ц Ципинова А.Х., Шериева Э.Х. // Современные наукоемкие технологии. 2016. № 8. C. 9-12.

2. Бокерия Л.А. Новикова С.П., Бокерия О.Л., Костров В.И. и др. // Бюллетень НЦССХ им. А.Н. Бакулева РАМН. 2014. Т. 15. № 4. C. 60-72.

3. Hubner P., Donati N., Quines L.K.M., Tessaro L.C. et al. // Mater. Sci. Eng. C Mater. Biol. Appl. 2020. Vol. 107. pp.110215.
4. Gaharwar A.K., Peppas N.A., Khademhosseini A. // Biotechnol. Bioeng. 2014. Vol. 111. pp. 441-453.

5. Помогайло А.Д. Полимерные иммобилизованные металлокомплексные катализаторы. М. Наука. 1988. 303 с.

6. Джеймс Т.X. Теория фотографического процесса. Ленинград. Химия. 1980. 672 с.

7. Лагута И.В., Ставинская О.Н., Кузема П.А., Казакова О.А. и др. // Физикохимия 
поверхности и защита материалов. 2017. Т. 53. № 5. C. 486-490.

8. Белкин Б.Л. // «Актуальные проблемы ветеринарной медицины», материалы международной научно-практической конференции. 25-26 сентября 2003 г. Ульяновск. 2003. T. 2. C. $87-88$.

9. Паничев А.М., Кулаков Ю.В., ков А.Н. // Тихоокеанский медицинский журнал. 2003. № 4. С. 21-24.

10. Fosso-Kankeu E., Mittal H., Waanders F., Roy S.S. // J. of Industrial and Engineering Chemistry. 2017. Vol. 48. pp. 151-161.

11. Sadeghinia A., Soltani S., Aghazadeh M., Khalilifard J. // J. of Biomedical Materials Research. Part A. 2020. Vol. 108. Is. 2. pp. 221233.

12. Olad A., Nouri N., Eslamzadeh M. // $S N$ Appl. Sci. 2019. Vol. 1. Iss. 8. 868.

13. Дабижа О.Н., Дербенева Т.В., Хатькова А.Н., Коновалова Н.А. // Известия СанктПетербургского государственного технологического института (технического универcumema). 2017. № 41 (67). C. 54-58.
14. Sokolova M.D., Davydova M.L., Shadrinov N.V. // Protection of metals and physical chemistry of surfaces. 2018. Vol. 54. No 5. pp. 845-852.

15. Липатов Ю.С. Физическая химия наполненных полимеров. М. Химия. 1977. 24 c.

16. Новый справочник химика и технолога. Основные свойства неорганических и органических и элементоорганических соединений. Санкт-Петербург. АНО НПО «Мир и Семья». 2002. 1276 с.

17. Smitha S., Mukundan P., Krishna Pillai P., Warrier K.G.K. // Mater. Chem. Phys. 2007. Vol. 103. Is. 2-3. pp. 318-322.

18. Малов А.Н., Неупокоева А.В. Желатин: получение, строение, свойства. В кн. Малов А.Н., Неупокоева А.В. Голографические регистрирующие среды на основе дихромированного желатина: супрамолекулярный дизайн и динамики записи. Иркутск: ИВВАИУ (ВИ). 2006. С. 25-69.

\title{
Sorption properties of gelatinous films modified by clinoptilolite rocks
}

\author{
(C) 2020 Dabizha O.N. ${ }^{1,2}$, Bityutskaya M.S. ${ }^{1}$ \\ ${ }^{1}$ Transbaikal State University, Chita, Russian Federation \\ ${ }^{2}$ Transbaikal Institute of Railway Transport, Chita, Russian Federation
}

This article is devoted to the problem of obtaining modified gelatin films with controlled swelling and dissolution. The mechanically activated high-silica (silicate module more than 4) clinoptilolite rocks, a highly dispersed fraction with a particle size of not more than 71 microns were used as modifiers in this study. The presence of surface silanol groups in clinoptilolite capable of interacting with the carboxyl or amino groups of gelatin macromolecules via intermolecular hydrogen bonds directly or through a layer of water molecules allows considering the possibility of additional structural strengthening. The purpose of this study was the synthesis of polymer-mineral materials based on gelatin and mechanically activated clinoptilolite rocks, as well as the investigation of the degree of swelling and dissolution of polymer-mineral films in aqueous media.

Filled polymer systems were prepared by mixing a gelatin solution with an aqueous suspension of a highly dispersed fraction of zeolites. The interaction of gelatin with a mechanically activated clinoptilolite filler will improve the interfacial adhesion and limit the mobility of polymer chains, which is equivalent to the formation of additional structural network nodes. Using optical microscopy and gravimetry, we studied the morphology of modified gelatin films and the sorption of water vapour and vapours of saturated sodium chloride and potassium chloridesolutions.

The presence of coagulation structures was revealed at the content of a mineral particulate filler of 0.5 wt. \% and the spherical shape of particles of the filler, relatively uniformly distributed in volumes of 2.5 and $5 \mathrm{~g} / \mathrm{dl}$ of gelatin matrices. It was revealed that films absorb water vapours better than vapours of saturated electrolyte solutions. It was found that the addition of $0.5 \mathrm{wt}$ \% mechanically activated clinoptilolite rocks in a gelatin solution of $5 \mathrm{~g} / \mathrm{dl}$ allowed obtaining films with a reduced degree of swelling. The degree of swelling was reduced by 8 times in water vapour and by at least 2-3 times in vapours of sodium chloride or potassium chloride. Taking into account the safety and excellent sorption properties of clinoptilolite rocks, the results obtained in this study can be recommended for use in general medicine and veterinary medicine.

Keywords: gelatin, zeolites, clinoptilolite, films, sorption properties, electrolytes, swelling in water, morphology. 


\section{References}

1. Azizov I.K.,

Tsipinova A.Kh., Sherieva E.Kh., Modern high technology, 2016, No. 8, pp. 9-12.

2. Bockeria L.A. Novikova S.P., Bockeria O.L., Kostrov V.I. et al., Bulletin of the NCCSX named after A.N. Bakuleva RAMS, 2014, Vol. 15, No 4, pp. 60-72.24.

3. Hubner P., Donati N., Quines L.K.M., Tessaro L.C. et al, Mater Sci Eng C Mater Biol Appl, 2020, Vol. 107, pp. 110215. doi: 10.1016/j.msec.2019.110215.

4. Gaharwar A.K., Peppas N.A., Khademhosseini A., Biotechnol. Bioeng, 2014, Vol. 111, pp. 441-453.

5. Pomogailo A.D. Polymer immobilized metal complex catalysts, M., Nauka, 1988, 303 p.

6. James T.H. Theory of the photographic process. Leningrad, Chemistry, 1980, $672 \mathrm{p}$.

7. Laguta I.V., Stavinskaya O.N., Kuzema P.A., Kazakova O.A. et al., Prot. met. phys. chem., 2017, Vol. 53, No 5, pp. 486-490.

8. Belkin B.L. // "Actual problems of veterinary medicine", Proceedings of the international scientific and practical conference, September 25-26, 2003, Ulyanovsk, 2003, Vol. 2, pp. 8788.

9. Panichev A.M., Kulakov Yu.V., Gulkov A.N., Pacific Medical J., 2003, No 4, pp. 21-24.

10. Fosso-Kankeu E., Mittal H., Waanders F., Roy S.S., J. of Industrial and Engineering Chemistry, 2017, Vol. 48, pp. 151-161.

Дабижа Ольга Николаевна - к.Х.Н., доцент, доцент кафедры химии, Забайкальский государственный университет, Чита, старший научный сотрудник научно-исследовательского проектно-технологического бюро «ЗабИЖТИнжиниринг», Чита

Битюцкая Марина Сергеевна - магистрант кафедры химии, Забайкальский государственный университет, Чита
11. Sadeghinia A., Soltani S., Aghazadeh M., Khalilifard J., J. of Biomedical Materials Research, Part A, 2020, Vol. 108, Is. 2, pp. 221233. doi.org/10.1002/jbm.a.36806

12. Olad A., Nouri N., Eslamzadeh M., $S N$ Appl. Sci., 2019, Vol. 1, Iss. 8, 868. https://doi.org/10.1007/s42452-019-0893-6.

13. Dabizha O.N., Derbeneva T.V., Khatkova A.N., Konovalova N.A., Proceedings of the St. Petersburg State Technological Institute (Technical University), 2017, No 41 (67), pp. 54-58.

14. Sokolova M.D., Davydova M.L., Shadrinov N.V., Protection of metals and physical chemistry of surfaces, 2018, Vol. 54, No 5, pp. 845-852.

15. Lipatov Yu.S. Physical chemistry of filled polymers, M., Chemistry, 1977, p. 24.

16. New reference chemist and technologist. The main properties of inorganic and organic and organoelement compounds. St. Petersburg, ANO NPO "Mir and Family", 2002, 1276 p.

17. Smitha S., Mukundan P., Krishna Pillai P. Warrier K.G.K., Mater. Chem. Phys., 2007, Vol. 103, Is. 2-3, pp. 318-322.

18. Malov A.N., Neupokoeva A.V. Gelatin: preparation, structure, properties. In: Malov A.N., Neupokoeva A.V. Holographic recording media based on dichromated gelatin: supramolecular design and dynamics of the recording. Irkutsk: Irkutskoe Vysshee Voennoe Aviatsionnoe Ingenernoe Uchilishche (Voennyy Institut), 2006, pp. 25-69.

Dabizha Olga N. - Candidate of Chemistry, Associate Professor, Associate Professor of the Department of Chemistry, Transbaikal State University, Chita, Senior Researcher of the research laboratory "Fundamental and Applied Physical and Chemical Materials Research" of the Research and Design Bureau "Zabizht-Engineering", Chita, email: dabiga75@mail.ru

Bityutskaya Marina S. - master student student of the Department of Chemistry, Transbaikal State University, Chita 